\title{
Early life determinants of physical activity in 11 to 12 year olds: cohort study
}

\author{
Calum Mattocks, research associate, ${ }^{1}$ Andy Ness, professor of epidemiology, ${ }^{2}$ Kevin Deere, research \\ assistant, ${ }^{1}$ Kate Tilling, senior lecturer in medical statistics, ${ }^{3}$ Sam Leary, statistician, ${ }^{1}$ \\ Steven N Blair, professor, ${ }^{4}$ Chris Riddoch, professor ${ }^{5}$
}

\section{'Department of Social Medicine, University of Bristol, Bristol BS8 1TQ \\ ${ }^{2}$ Department of Oral and Dental Science, Bristol Dental School \\ ${ }^{3}$ Department of Social Medicine, University of Bristol, Bristol BS8 2PR \\ ${ }^{4}$ Department of Exercise Science, Arnold School of Public Health, University of South Carolina, USA \\ ${ }^{5}$ Sport and Exercise Science, School for Health, \\ University of Bath \\ Correspondence to: $\mathrm{C}$ Mattocks c.mattocks@bristol.ac.uk}

doi:10.1136/bmj.39385.443565.BE

\section{ABSTRACT}

Objective To examine factors in early life (up to age 5 years) that are associated with objectively measured physical activity in 11-12 year olds.

Design Prospective cohort study.

Setting Avon longitudinal study of parents and children, United Kingdom.

Participants Children aged 11-12 years from the Avon longitudinal study of parents and children.

Main outcome measure Physical activity levels in counts per minute (cpm) and minutes of moderate to vigorous physical activity for seven days measured with a uniaxial actigraph accelerometer.

Results Valid actigraph data, defined as at least three days of physical activity for at least 10 hours a day, were collected from 5451 children. Several factors were associated with physical activity at ages $11-12$ years. Regression coefficients are compared with the baseline of "none" for categorical variables: maternal brisk walking during pregnancy (regression coefficient 5.0, 95\% confidence interval -8.5 to 18.5 ; cpm for $<1 \mathrm{~h} / \mathrm{wk}$ and $\geq 2$ h/wk of physical activity $17.7,5.3$ to 30.1 ), maternal swimming during pregnancy $(21.5,10.9$ to 32.1 and cpm for $<1 \mathrm{~h} /$ wk and $\geq 2 \mathrm{~h} / \mathrm{wk}$ of physical activity $24.2,7.8$ to 40.7), parents' physical activity when the child was aged 21 months $(28.5,15.2$ to 41.8 and cpm of physical activity for either parent active and both parents active $33.5,17.8$ to 49.3 ), and parity assessed during pregnancy $(2.9,-7.6$ to 13.4 and $c p m$ of physical activity for 1 and $\geq 2$ parity $21.2,7.1$ to 35.3 ).

Conclusions Few factors in early life predicted later physical activity in 11-12 year olds. Parents' physical activity during pregnancy and early in the child's life showed a modest association with physical activity of the child at age 11-12 years, suggesting that active parents tend to raise active children. Helping parents to increase their physical activity therefore may promote children's activity.

\section{INTRODUCTION}

Regular physical activity is beneficial to the health of adults and is thought to be beneficial to the health of children. ${ }^{12}$ Although there is less evidence of the benefit to children, ${ }^{3}$ activity in childhood may be an important determinant of health in adulthood for several reasons.
A systematic review of physical activity in adolescents and health suggests direct and indirect pathways by which physical activity in youth might affect later health. ${ }^{4}$ Some risk factors for diseases as adults are associated with lower levels of physical activity in childhood. $^{5-7}$ Thus a hypothetical pathway for disease could be from fetal and early life factors to physical activity in childhood to childhood risk factors for disease in adulthood to disease in adulthood. ${ }^{8}$ In support of this hypothetical pathway, associations have been reported between early life factors and childhood obesity. For example, birth weight and parental obesity both predict a child's obesity at age seven. ${ }^{9}$ Some evidence also shows that premature babies have poorer motor coordination in childhood ${ }^{10}$ and that such children may be less active than their peers. ${ }^{11}$

Physical activity is a complex multifactorial behaviour that is influenced by environmental and biological factors. ${ }^{12}$ Although there is an extensive literature on the psychosocial and environmental factors that influence physical activity in children, much of it is cross sectional ${ }^{13}$ and little is known about early life influences on children's physical activity. ${ }^{8}$ One prospective study found that risk factors in early life for a sedentary lifestyle $(<300$ minutes of self reported physical activity per week) at age 10-12 years were being female, being the oldest sibling, having a high family income at birth, high maternal education at birth, and lower maternal reported physical activity of children at age 4 years. ${ }^{8}$ To our knowledge no study has examined the influences in early life on children's objectively measured physical activity in a contemporary cohort with extensive data on early life. Objective methods of measuring physical activity have advantages over subjective methods, particularly in children, and should enable the nature of the associations between physical activity and health to be characterised more precisely. ${ }^{14}$

We examined the factors in early life (up to age 5 years) that are associated with objectively measured physical activity in a large contemporary cohort of children aged 11-12 years.

\section{METHODS}

The Avon longitudinal study of parents and children (ALSPAC) is a geographically based birth cohort that 
has been described in detail previously. ${ }^{15}$ Briefly, all pregnant women in the former Avon health area who had an expected delivery date between 1 April 1991 and 31 December 1992 were invited to take part in the study. Overall, 14541 women were enrolled, totalling 14062 live births.

From pregnancy and continuing to this day, questionnaires have been sent to the mothers, their partners (the partner at the time the questionnaire was administered may not have been the biological father), and the children inquiring about their health and lifestyle, the parents' circumstances, and the health and development of the child. Since age 7 the children have been invited to research clinics for a series of physiological and psychometric measures. The children gave written assent from age 10 (cosigned by the main carer). For the study on physical activity verbal consent was given by the child and main carer.

Physical activity data

Children who attended the study clinic at age 11 were asked to wear an actigraph accelerometer (Actigraph
AM7164 2.2; LLC, Fort Walton Beach, Fl) for seven days. The methods are described elsewhere. ${ }^{16}$ Briefly, the actigraphs were initialised to start recording at 5 am on the day after the clinic visit. The children were given a timesheet to record the times that the actigraph was put on and taken off each day. They were also asked to record any times (in minutes) that they swam or cycled each day as the actigraph does not record cycling well and cannot be worn for swimming. The actigraphs were downloaded on to a computer and a customised macro was used to derive a series of variables describing levels and patterns of physical activity. Two outcome variables were used in this analysis: average counts per minute (cpm) over the valid measurement period - a measure of total activity that has been validated against activity energy expenditure estimated by doubly labelled water $(\mathrm{r}=0.54 ; \mathrm{P}<0.01)^{17}$; and moderate to vigorous physical activity, as current recommendations for physical activity in children are framed in terms of time spent each day in such activity. ${ }^{1}$ We used a cut-off point of cpm greater than 3600 to define moderate to vigorous physical activity. ${ }^{18}$

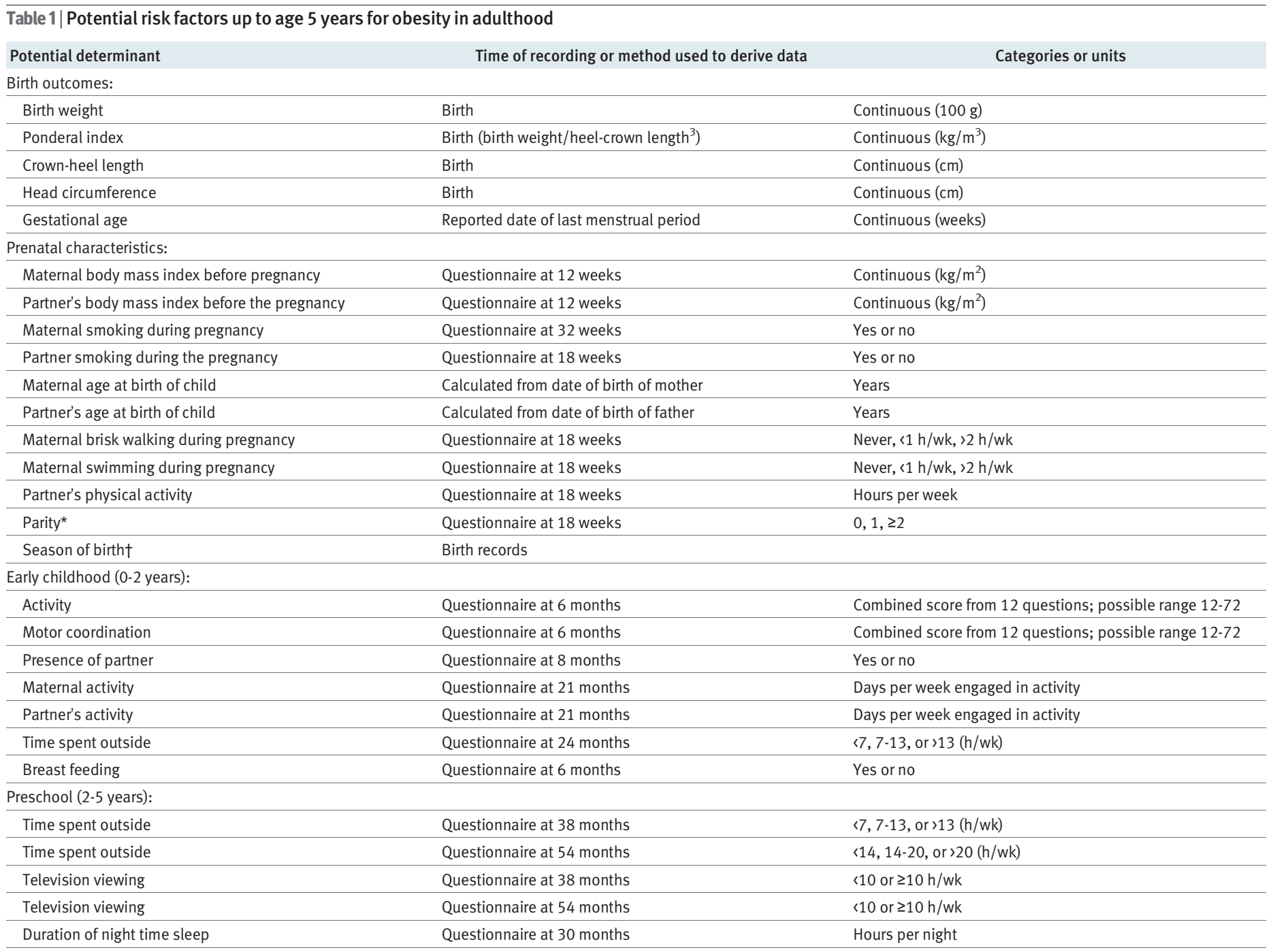

*Number of previous pregnancies resulting in live birth or still birth.

†Winter=December to February; spring=March to May; summer=June to August; autumn=September to November. ${ }^{22}$ 
Table 2 | Children in Avon longitudinal study of parents and children who attended research clinic and had valid data on physical activity compared with those who did not at age 11-12 years. Values are numbers (percentages) unless stated otherwise

\begin{tabular}{|c|c|c|c|c|c|}
\hline Characteristic & No of children & $\begin{array}{l}\text { No valid data } \\
\quad(n=1451)\end{array}$ & No of children & Valid data $(n=5451)$ & $P$ value \\
\hline \multicolumn{6}{|l|}{ Child variables: } \\
\hline Mean (SD) body mass index $\left(\mathrm{kg} / \mathrm{m}^{2}\right)$ & 1417 & $19.5(3.8)$ & 5388 & $19.0(3.3)$ & $<0.001$ \\
\hline Mean (SD) birth weight (g) & 1414 & $3445(537)$ & 5121 & $3433(523)$ & 0.43 \\
\hline Social class*: & 1272 & & 4806 & & \\
\hline I and II & 353 & 27.8 & 1428 & 29.7 & \multirow{3}{*}{0.19} \\
\hline III, non-manual & 333 & 26.2 & 1308 & 27.2 & \\
\hline III, manual & 375 & 29.5 & 1279 & 26.6 & \\
\hline O level & 358 & 26.6 & 1343 & 26.7 & \multirow{3}{*}{0.04} \\
\hline Vocational & 464 & 34.4 & 1798 & 35.8 & \\
\hline None or CSE & 330 & 24.5 & 1063 & 21.1 & \\
\hline
\end{tabular}

We deleted from each file 10 or more minutes of consecutive zeros as we regarded these as periods when the monitor was not worn. ${ }^{19}$ We also excluded any day of recording when the average cpm was less than 150 or more than 3 standard deviations above the mean ${ }^{20}$ as we considered this level of physical activity to be behaviourally implausible. We considered activity data to be valid if the recording period was for at least 10 hours per day for at least three days. ${ }^{16}$ The actigraphs were recalibrated when the batteries were changed - about every six months. Over the two year period of data collection, 267 actigraphs were used. Of the 518 calibrations, no adjustment was required in 394 (77\%) cases.

Potential risk factors

We defined early life as the period from pregnancy to age 5 years as this includes some suggested critical periods of development: the intrauterine period, infancy, and the age of adiposity rebound. Age 5 is also a landmark for children as they start school and therefore their lives change noticeably. Potential risk factors were identified as characteristics in early life that were associated with physical activity in childhood, ${ }^{8}$ obesity, ${ }^{9}$ or other markers of the metabolic syndrome $^{56}$; cardiorespiratory fitness or neuromotor function ${ }^{10}$; or activity behaviours that are known to display some tracking from early to later childhood. ${ }^{821}$ Table 1 lists the potential risk factors, how they were derived, and the units used.

\section{Potential confounders}

We recorded socioeconomic variables at 32 weeks' gestation. The mother was asked to record her highest education level, which was categorised into none or CSE (exams at age 16), vocational, $\mathrm{O}$ level (exams at age 16, higher than CSE), A level (exams at age 18), or university degree. Social class groups were derived from the parents' occupation (classes I to V with III split into non-manual and manual) using the 1991 Office of Population Censuses and Surveys. ${ }^{23}$ When the social class of the mother and partner differed, the lower of the two was used in the analysis to give the most variability within the variable.

\section{Statistical analysis}

We used three models to explore the role of confounders, with cpm as the outcome. Model 1 was adjusted

Table 3 Associations between birth outcomes and counts per minute of physical activity in children aged 11-12 years from Avon longitudinal study of parents and children

\begin{tabular}{|c|c|c|c|c|c|c|}
\hline \multirow[b]{2}{*}{ Variable } & \multicolumn{3}{|c|}{ Model 1} & \multicolumn{3}{|c|}{ Model 2} \\
\hline & $\begin{array}{l}\text { No of } \\
\text { children }\end{array}$ & Regression coefficient* $(95 \% \mathrm{Cl})$ & $P$ value & $\begin{array}{l}\text { No of } \\
\text { children }\end{array}$ & $\begin{array}{c}\text { Regression coefficient* } \\
(95 \% \mathrm{Cl})\end{array}$ & P value \\
\hline Birth weight (100 g) & 5058 & $-2.1(-6.7$ to 2.6$)$ & 0.383 & 4671 & $-0.4(-6.3$ to 5.5$)$ & 0.893 \\
\hline Ponderal index $\left(\mathrm{kg} / \mathrm{m}^{3}\right)$ & 4045 & $1.3(-3.4$ to 6.0$)$ & 0.600 & 3738 & $1.0(-3.8$ to 5.9$)$ & 0.670 \\
\hline Head circumference $(\mathrm{cm})$ & 4144 & $-5.2(-10.8$ to 0.3$)$ & 0.063 & 3834 & $-3.5(-9.2$ to 2.2$)$ & 0.233 \\
\hline Crown-heel length $(\mathrm{cm})$ & 4094 & $-3.6(-9.4$ to 2.1$)$ & 0.217 & 3786 & $-1.9(-7.9$ to 4.0$)$ & 0.521 \\
\hline Gestation (weeks) & 5127 & $-1.3(-6.1$ to 3.5$)$ & 0.599 & 4739 & $-2.4(-7.7$ to 2.9$)$ & 0.376 \\
\hline
\end{tabular}

Model 1 adjusted for age and sex. Model 2 adjusted for age, sex, and parental social class by occupation and mother's education.

* Standardised regression coefficient: change in counts per minute per standard deviation of variable: birth weight 5.2, ponderal index 3.1, head circumference 1.5 , crown-heel length 2.4 , and gestation 1.8 . 
for age and sex. Model 2 was adjusted for age, sex, maternal education, and social class. We have previously shown that physical activity is negatively associated with socioeconomic status and that boys are more active than girls in this population: median $644 \mathrm{cpm}$ (interquartile range 528-772) for boys and $529 \mathrm{cpm}$ (444638) for girls; $\mathrm{P}<0.001 .{ }^{24}$ We therefore included sex and socioeconomic status as potential confounders rather than as potential determinants. Model 3 was adjusted for the confounders in model 1 but restricted to those with all available data from model 2. Measures of size at birth were additionally adjusted for gestational age. Season of birth was additionally adjusted for season of measurement, as all children were seen at about age 11 years and 9 months, so season of birth is likely to be related to season of measurement. Models were run separately for each characteristic - that is, they were not mutually adjusted. Analysis for models 1 and 2 was repeated with minutes of moderate to vigorous physical activity as the outcome. We repeated analyses in children who did not report swimming or cycling during the period of measurement. Analyses were carried out on boys and girls combined. To test for an effect modification of sex we introduced interaction terms ( $\operatorname{sex}^{\times} \mathrm{ex}^{-}$ posure variable) into model 1 . When evidence of an interaction existed we did the analyses separately for boys and girls. Moderate skewness was found in the activity variables. We did not transform data for the analyses but we did use robust standard errors. Such errors allow derivation of confidence intervals and standard errors on the basis of the actual distribution of the outcome variable in the dataset, rather than on an assumed underlying probability distribution..$^{25}$ We present the results for continuous variables as standardised regression coefficients, adjusted for the standard deviation of cpm for each model. Thus the regression coefficient for continuous variables is the difference in cpm associated with a 1 standard deviation change in the exposure variable. We present the results for categorical variables as normal regression coefficients.

\section{RESULTS}

A total of 11952 children from the Avon longitudinal study of parents and children were invited to participate in study clinics at age 11 years. Of these, 7159 (59.9\%) attended the clinic and $6622(92.5 \%)$ agreed to wear an actigraph accelerometer. Of the children who agreed to participate, $5595(84.5 \%)$ returned actigraphs that satisfied the validity criteria. ${ }^{16}$ Children from multiple births, totalling 144, were excluded from the analyses to rule

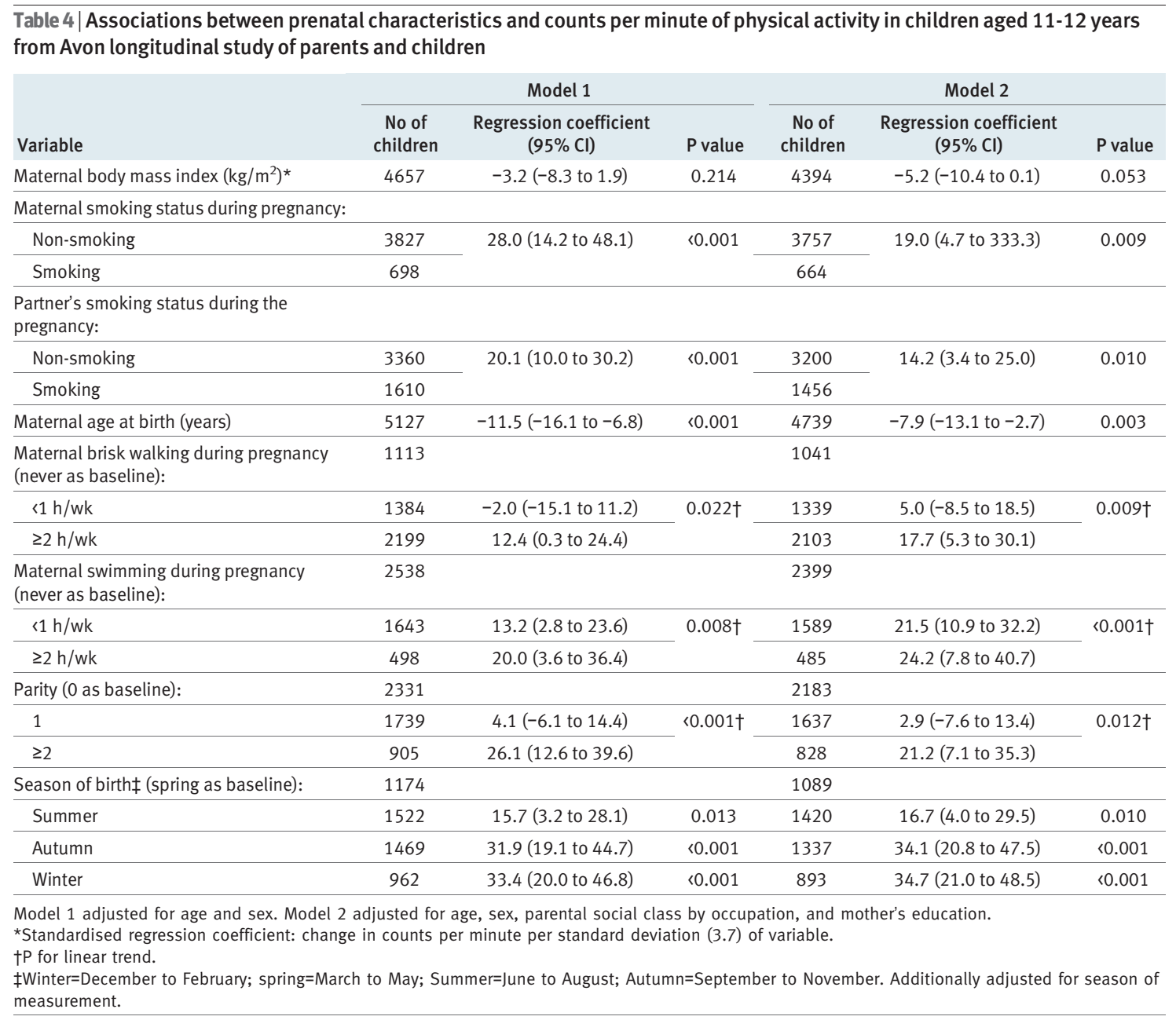


out non-independence in the data. The sample consisted of 5451 children (2593 boys and 2858 girls), mean age 11.8 years. Some small differences were found between the characteristics of children who provided valid data on physical activity and those who did not (table 2).

Tables 3-7 show the associations between variables and cpm for each model for each of the critical developmental periods. Results were similar after excluding children who reported swimming or cycling during the measurement period (data not shown). Results from model 3 were similar to those of model 1 (data not shown). Results for models 1 and 2 with moderate to vigorous physical activity as the outcome showed a similar pattern to cpm as the outcome. Therefore, only the results for counts per minute (cpm) are shown.

None of the birth outcomes was associated with physical activity at ages 11-12 years and this remained unchanged after adjustment for confounders (table 3).

Few of the prenatal characteristics were associated with physical activity (table 4 ). Mother's body mass index before pregnancy, parents' smoking status during pregnancy, mother's age at birth of the child, mother's physical activity, parity, and season of birth showed modest associations with physical activity. The associations for parents' smoking and maternal age attenuated after adjustment for socioeconomic status, whereas the associations for maternal physical activity during pregnancy strengthened slightly. Partner's body mass index, obesity in the mother and her partner, partner's age at birth, partner's physical activity, and presence of the mother's partner at home were not associated with later physical activity (data not shown).
Table 5 shows the associations between characteristics in childhood from age 0-2 years and physical activity. These associations tended to be modest and remained after adjustment. Parental activity was associated with later physical activity in the child.

Of the characteristics in preschool aged children, only television viewing at 38 and 54 months' follow-up showed any clear associations, although these were small. Little evidence was found that the other proxy measures of physical activity, time spent outside at 38 and 54 months, were associated with later physical activity.

Evidence was found of an interaction in only two of the variables so the results are presented for the analyses of boys and girls combined. Sex $\times$ brisk walking and sex $\times$ motor coordination showed evidence of effect modification $(\mathrm{P}=0.020$ and $\mathrm{P}=0.008)$. Table 7 shows the analyses for boys and girls separately when the exposure variable was modified by sex.

\section{DISCUSSION}

Few of the early life factors studied were associated with later physical activity in 11-12 year olds and for those that were the associations were modest.

\section{Birth outcomes and prenatal exposures}

None of the birth outcomes was associated with physical activity. A recent study found that children of low birth weight $(<2500 \mathrm{~g})$ reported slightly fewer minutes of activity per week at age 10-12 than their peers of higher birth weight. The same study, however, reported no difference in sedentary lifestyle by birth weight. ${ }^{8}$

\begin{tabular}{|c|c|c|c|c|c|c|}
\hline \multirow[b]{2}{*}{ Variable } & \multicolumn{3}{|c|}{ Model 1} & \multicolumn{3}{|c|}{ Model 2} \\
\hline & $\begin{array}{l}\text { No of } \\
\text { children }\end{array}$ & $\begin{array}{l}\text { Regression coefficient } \\
\qquad(95 \% \mathrm{Cl})\end{array}$ & $P$ value & $\begin{array}{l}\text { No of } \\
\text { children }\end{array}$ & $\begin{array}{l}\text { Regression coefficient } \\
\qquad(95 \% \mathrm{Cl})\end{array}$ & $P$ value \\
\hline Activity at 6 months* & 4574 & $-2.13(-6.99$ to 2.72$)$ & 0.389 & 4303 & $-1.49(-6.49$ to 3.50$)$ & 0.558 \\
\hline Motor coordination at 6 months* & 4736 & $5.33(0.12$ to 10.54$)$ & 0.045 & 4452 & 5.77 (0.25 to 11.29$)$ & 0.041 \\
\hline \multicolumn{7}{|l|}{ With partner at 8 months: } \\
\hline Yes & 4675 & \multirow[t]{2}{*}{$23.6(-3.4$ to 50.5$)$} & \multirow[t]{2}{*}{0.086} & 4422 & \multirow[t]{2}{*}{$9.5(-21.5$ to 40.5$)$} & \multirow[t]{2}{*}{0.547} \\
\hline No & 138 & & & 103 & & \\
\hline $\begin{array}{l}\text { Parents activity at } 21 \text { months (neither active as } \\
\text { baseline): }\end{array}$ & \multicolumn{2}{|l|}{917} & \multicolumn{3}{|c|}{866} & \\
\hline Either active & 1968 & 29.4 (16.2 to 42.5$)$ & \multirow[t]{2}{*}{$<0.001 \dagger$} & 1876 & 28.5 (15.2 to 41.8$)$ & \multirow[t]{2}{*}{$<0.001 \dagger$} \\
\hline Both active & 881 & $31.5(16.1$ to 46.8$)$ & & 844 & $33.5(17.8$ to 49.3$)$ & \\
\hline $\begin{array}{l}\text { Time outside at } 24 \text { months ( } 67 \mathrm{~h} / \mathrm{wk} \text { as } \\
\text { baseline): }\end{array}$ & \multicolumn{2}{|l|}{1026} & \multicolumn{3}{|c|}{946} & \\
\hline $7-13 \mathrm{~h} / \mathrm{wk}$ & 1284 & $-15.5(-29.1$ to -1.8$)$ & \multirow[t]{2}{*}{$0.085 \dagger$} & 1224 & $-12.9(-27.1$ to 1.2$)$ & \multirow[t]{2}{*}{$0.196 \dagger$} \\
\hline$>13 \mathrm{~h} / \mathrm{wk}$ & 2349 & $-8.5(-21.0$ to 3.9$)$ & & 2211 & $-6.6(-19.5$ to 6.4$)$ & \\
\hline $\begin{array}{l}\text { Breast fed at } 6 \text { months (still breast feeding as } \\
\text { baseline): }\end{array}$ & \multicolumn{2}{|l|}{1703} & \multicolumn{3}{|c|}{1629} & \\
\hline Yes & 2309 & $7.2(-3.3$ to 17.7$)$ & \multirow[t]{2}{*}{$0.238 \dagger$} & 2157 & $-1.3(-12.4$ to 9.8$)$ & \multirow[t]{2}{*}{$0.749 \dagger$} \\
\hline Never & 817 & $10.9(-3.2$ to 25.0$)$ & & 749 & $-5.9(-21.5$ to 9.6$)$ & \\
\hline \multicolumn{7}{|c|}{$\begin{array}{l}\text { Model } 1 \text { adjusted for age and sex. Model } 2 \text { adjusted for age, sex, parental social class by occupation, and mother's education. } \\
\text { *Standardised regression coefficient: change in counts per minute per standard deviation of variable: activity at } 6 \text { months } 6.3 \text { and motor coordination } \\
\text { at } 6 \text { months } 5.2 \text {. } \\
\text { †P for linear trend. }\end{array}$} \\
\hline
\end{tabular}


Table 6 | Associations between exposures in preschool children (2-5 years) and counts per minute of physical activity in children aged 11-12 years from Avon longitudinal study of parents and children

\begin{tabular}{|c|c|c|c|c|c|c|}
\hline Variable & \multicolumn{3}{|c|}{ Model 1} & \multicolumn{3}{|c|}{ Model 2} \\
\hline $7-13 \mathrm{~h} / \mathrm{wk}$ & 1101 & $-4.1(-16.8$ to 8.5$)$ & \multirow[t]{2}{*}{$0.588^{*}$} & 1043 & $-4.4(-17.4$ to 8.6$)$ & \multirow[t]{2}{*}{$0.230^{\star}$} \\
\hline$>13 \mathrm{~h} / \mathrm{wk}$ & 1569 & $-5.6(-16.8$ to 5.5$)$ & & 1464 & $-10.2(-21.8$ to 1.5$)$ & \\
\hline $14-20 \mathrm{~h} / \mathrm{wk}$ & 1531 & $14.2(0.7$ to 27.6$)$ & \multirow[t]{2}{*}{$0.112^{*}$} & 1439 & $9.0(-4.9$ to 22.9$)$ & \multirow[t]{2}{*}{$0.436^{*}$} \\
\hline$>20 \mathrm{~h} / \mathrm{wk}$ & 1956 & $10.6(-2.4$ to 23.5$)$ & & 1849 & $4.6(-8.8$ to 17.9$)$ & \\
\hline \multicolumn{7}{|l|}{ Television viewing at 38 months: } \\
\hline$<10 \mathrm{~h} / \mathrm{wk}$ & 3566 & $-6.1(-18.0$ to 5.9$)$ & 0.318 & 3367 & $-12.4(-24.9$ to 0.1$)$ & 0.051 \\
\hline$<10 \mathrm{~h} / \mathrm{wk}$ & 1432 & \multirow[t]{2}{*}{$-4.7(-15.0$ to 5.7$)$} & \multirow[t]{2}{*}{0.375} & 1354 & \multirow[t]{2}{*}{$-11.0(-21.8$ to -0.2$)$} & \multirow[t]{2}{*}{0.046} \\
\hline$>10 \mathrm{~h} / \mathrm{wk}$ & 3035 & & & 2853 & & \\
\hline Sleep at 30 months (hours per night) $†$ & 4589 & $3.0(-1.8$ to 7.8$)$ & 0.218 & 4310 & $-0.55(-5.8$ to 4.7$)$ & 0.837 \\
\hline
\end{tabular}

Model 1 adjusted for age and sex. Model 2 adjusted for age, sex, parental social class by occupation, and mother's education.

*P for linear trend.

†Standardised regression coefficient: change in counts per minute per standard deviation (0.96) of variable.

Body mass index of the mother before pregnancy but not her partner was weakly associated with physical activity. Previous studies have been inconsistent. One reported no relation between parental obesity and physical activity, assessed by heart rate monitor in 101 prepubescent girls. ${ }^{26}$ A systematic review found that parental obesity was positively associated with physical activity in 4-12 year olds. ${ }^{13}$

Smoking in the mother and her partner were both positively associated with physical activity. This is surprising because maternal smoking during pregnancy is associated with childhood obesity. ${ }^{9}$ The association we have shown was similar for smoking in both the mother and the partner and attenuated after adjustment, so may be a result of the social patterning of smoking behaviour. We have previously shown a negative association between physical activity and socioeconomic status. ${ }^{24}$

Previous studies have reported a positive association between parental activity and children's activity although there is some inconsistency. Eleven of 29 studies in a systematic review showed a positive association between parental physical activity and children's physical activity whereas findings in the remainder were equivocal. ${ }^{13}$ In our study, maternal activity during pregnancy (specifically brisk walking and swimming) was positively associated with physical activity in the children. It is unlikely that this is due to biological factors in utero but is more likely that physical activity during pregnancy is a marker for later maternal physical activity and that this in turn influences children's physical activity.

Parity is also a measure of the number of older siblings and we found that physical activity was positively associated with parity. This confirms the findings of a previous study, which reported that birth order was positively associated with physical activity and negatively associated with a sedentary lifestyle in 10-12 year olds. ${ }^{8}$

The association with season of birth is difficult to explain. Children born during summer to winter were more active than those born in spring. Season of birth is associated with a range of mental and physical disorders. ${ }^{27}$ It is possible that season of birth has an effect through the age at which children start school. In this study some children were measured while at primary school and some while at secondary school,

\begin{tabular}{|c|c|c|c|c|c|c|}
\hline Variable & \multicolumn{3}{|c|}{ Boys } & \multicolumn{3}{|c|}{ Girls } \\
\hline $\begin{array}{l}\text { Maternal brisk walking during } \\
\text { pregnancy (never as baseline): }\end{array}$ & 517 & & & 596 & & \\
\hline$\geq 2 \mathrm{~h} / \mathrm{wk}$ & 1074 & $-0.6(-19.9$ to 18.7$)$ & & 1125 & 24.4 (9.4 to 39.4$)$ & \\
\hline Motor coordination $†$ & 2266 & $-1.55(-9.57$ to 6.45$)$ & 0.703 & 2470 & 11.63 (4.86 to 18.40$)$ & 0.001 \\
\hline
\end{tabular}




\section{WHAT IS ALREADY KNOWN ON THIS TOPIC}

Identifying factors that influence physical activity in childhood may help develop better intervention strategies

Little is known about whether factors in early childhood might influence later physical activity

\section{WHAT THIS STUDY ADDS}

Factors in early life have limited influence on later physical activity in 11-12 year olds

Parental physical activity is associated with modest increases in children's activity

Encouraging activity among parents may help children to be active

where the environments may provide different opportunities for physical activity. It was not, however, possible to control for school type in this analysis. It is also known that a month of birth bias exists in many competitive sports, with those born earlier in the sports' season more likely to succeed at competitive sport ${ }^{28}$ and it may be that early involvement in organised sport leads to increased physical activity in later life. ${ }^{29}$

Early childhood (0-2 years) and preschool (2-5 years) None of the indicators of physical activity at age 0-2 years (activity at six months or time outside at 24 months) was associated with later physical activity. Tracking of physical activity tends to be weak to moderate $^{2130}$ and it may be that the early measures of physical activity we chose lacked precision to detect an association with later physical activity. Parental physical activity at 21 months was associated with children's physical activity when two non-active parents were compared with either or both parents being active. Studies have reported that physical activity tends to aggregate in families. ${ }^{31}$ A review, however, reported that the evidence for an association between parental and child's physical activity is limited. ${ }^{32} \mathrm{~A}$ small association was found with motor coordination at six months. This is in agreement with a recent study that found a weak association between physical activity and motor skills. ${ }^{11}$

Few of the characteristics in preschool aged children (2-5 years) were associated with later physical activity. A small association was found, after adjustment, with television viewing at 38 and 54 months. One study recently reported no cross sectional association between television viewing and objectively measured physical activity. ${ }^{33} \mathrm{~A}$ meta-analysis that included mainly cross sectional studies reported a weak relation between television viewing and physical activity (Pearson's coefficient $r=-0.096,95 \%$ confidence interval -0.080 to -0.112$).{ }^{34}$ The modest associations we report here may result from the length of time between measures for television viewing and assessment of physical activity, as other factors may have had a greater influence before follow-up at 11 to 12 years.

Effect modification by sex

We found little evidence of effect modification by sex on most of the variables. Owing to the large number of tests for interaction it is possible that those showing evidence of effect modification did so by chance. We did find strong evidence of an association between maternal brisk walking during pregnancy and physical activity in girls but not in boys. A previous review reported that maternal physical activity is associated with physical activity in daughters more than in sons. ${ }^{32}$

\section{Strengths and limitations of the study}

The use of an objective measure of physical activity is a major strength of this study as it provides a more precise and accurate estimate than self report of the level of physical activity. The detailed measures available and the large sample size allowed us to test for associations of several potential determinants and allowed adequate exploration of the role of potential confounders.

Some of the variables were based on single questions therefore not validated questionnaires. This may have resulted in attenuated associations with children's physical activity owing to imprecision of measurement. ${ }^{14} \mathrm{It}$ is also possible that cohort attrition and biased participation in study resulted in an unrepresentative sample, which may limit generalisability. Children who participated in this study were more likely to be from socially advantaged backgrounds, ${ }^{16}$ although the magnitude of social patterning in physical activity is small. ${ }^{24}$ Several of the characteristics were based on questionnaires in which the questions changed slightly over time, making comparisons difficult.

\section{Conclusions}

We have shown that early life factors have limited influence on later physical activity in 11-12 year olds. This may have implications when developing guidelines for interventions to increase physical activity, as focusing on modifiable early life factors may have only a modest effect on later levels of physical activity. We have shown that children are slightly more active if their parents are active early in the child's life. This suggests that encouraging physical activity in parents may also influence their children to become more active, with the added advantage that physically active parents are healthier. Although we report few associations between early life factors and physical activity, future research should re-examine these associations in later adolescence when physical activity declines, particularly in girls.

We thank the families who took part and the midwives for their help in recruiting them. The Avon longitudinal study of parents and children team includes interviewers, computer and laboratory technicians, clerical workers, research scientists, volunteers, managers, receptionists, and nurses. The UK Medical Research Council, the Wellcome Trust and the University of Bristol provide core support for the Avon longitudinal study of parents and children.

Contributors: CM organised the daily data collection tasks; was in charge of clinic organisation, preparation of activity monitors, and supporting documentation for each child; and carried out statistical analyses. He is guarantor. CR was the lead applicant for grant funding; was responsible for the overall design of measurement protocols, data collection, and analysis; organised the ethical procedures; and liaised with the funding body. KD participated in daily collection tasks, helped prepare the activity monitors and supporting documentation for each child, and provided input on drafts of this paper. KT was an applicant for grant funding, had overall responsibility for statistical analyses, and provided input on drafts of this paper. SL assisted with 
statistical analyses and provided input on drafts of this paper. SNB was a collaborator on the grant; provided scientific input on all aspects of the study design, analysis, and reporting; and provided input on drafts of this paper. AN was an applicant for grant funding; provided input on all aspects of the study design and drafts of this paper; and was responsible for the management of data collection on physical activity.

Funding: The Avon longitudinal study of parents and children has core support from the Medical Research Council and the Wellcome Trust. The UK

Department of Health, the Department of the Environment, the Department for Education and Employment, the National Institutes of Health, and a variety of medical research charities and commercial companies have supported individual projects. This research was funded by a grant from the US National Heart, Lung, and Blood Institute (R01HL071248-01A1).

Competing interests: None declared.

Ethical approval: This study was approved by the law and ethics committee for the Avon longitudinal study of parents and children and local research ethics committees.

Provenance and peer review: Not commissioned; externally peer reviewed.

1 Department of Health. At least five a week: evidence on the impact of physical activity and its relationship to health. London: DoH, 2004.

2 Strong WB, Malina RM, Blimkie CJR, Daniels SR, Dishman RK, Gutin B, et al. Evidence based physical activity for school-age youth. J Pediatr 2005;146:732-7.

3 Twisk JW. Physical activity guidelines for children and adolescents: a critical review. Sports Med 2001;31:617-27.

4 Hallal PC, Victora CG, Azevedo MR, Wells JCK. Adolescent physical activity and health: a systematic review. Sports Med 2006;36:1019-30.

5 Brage S, Wedderkopp N, Ekelund U, Franks PW, Wareham NJ, Andersen LB, et al. Features of the metabolic syndrome are associated with objectively measured physical activity and fitness in Danish children: the European youth heart study (EYHS). Diabetes Care 2004;27:2141-8.

6 Nassis GP, Papantakou K, Skenderi K, Triandafillopoulou M, Kavouras SA, Yannakoulia M, et al. Aerobic exercise training improves insulin sensitivity without changes in body weight, body fat, adiponectin, and inflammatory markers in overweight and obese girls. Metabolism 2005; 54:1472-9.

7 Andersen LB, Harro M, Sardinha LB, Froberg K, Ekelund U, Brage S, et al. Physical activity and clustered cardiovascular risk in children: a cross-sectional study (the European youth heart study). Lancet 2006;368:299-304.

8 Hallal PC, Wells JCK, Reichert FF, Anselmi L, Victora CG. Early determinants of physical activity in adolescence: prospective birth cohort study. BMJ 2006;332:1002-7.

9 Reilly JJ, Armstrong J, Dorosty AR, Emmett PM, Ness A, Rogers I, et al. Early life risk factors for obesity in childhood: cohort study. BMJ 2005;330:1357.

10 Hebestreit H, Bar-Or O. Exercise and the child born prematurely. Sports Med 2001;31:591-9.

11 Fisher A, Reilly JJ, Kelly LA, Montgomery C, Williamson A, Paton JY, et al. Fundamental movement skills and habitual physical activity in young children. Med Sci Sport Exerc 2005;37:684-8.

12 Thorburn AW, Proietto J. Biological determinants of spontaneous physical activity. Obes Rev 2000;1:87-94

13 Sallis JF, Prochaska JJ, Taylor WC. A review of correlates of physical activity of children and adolescents. Med Sci Sport Exerc 2000;32:963-75.

14 Wareham NJ, Rennie KL. The assessment of physical activity in individuals and populations: why try to be more precise about how physical activity is assessed? Int J Obes 1998;22(suppl 2):S30-8.
15 Golding J, Pembrey M, Jones R. ALSPAC - the Avon longitudinal study of parents and children. I. Study methodology. Paediatr Perinat Epidemiol 2001;15:74-87.

16 Mattocks C, Ness A, Leary S, Tilling K, Blair SN, Shield J, et al. Use of accelerometers in a large field based study of children: protocols, design issues and effects on precision. J Phys Act Health 2008;5 (suppl 1): S94-107.

17 Ekelund U, Sjostrom M, Yngve A, Poortvliet E, Nilsson A, Froberg K, et al. Physical activity assessed by activity monitor and doubly labeled water in children. Med Sci Sport Exerc 2001;33:275-81.

18 Mattocks C, Ness A, Leary S, Tilling K, Deere K, Kirkby J, et al. Calibration of an accelerometer during free-living activities in children. Int J Pediatr Obes 2007; doi: 10.1080/ 17477160701408809.

19 Riddoch CJ, Bo Andersen L, Wedderkopp N, Harro M, Klasson-Heggebo L, Sardinha LB, et al. Physical activity levels and patterns of 9- and 15-yr-old European children. Med Sci Sport Exerc 2004;36:86-92.

20 Tremblay MS, Barnes JD, Copeland JL, Esliger DW. Conquering childhood inactivity: is the answer in the past? Med Sci Sport Exerc 2005;37:1187-94.

21 Kristensen PL, Moller NC, Korsholm L, Wedderkopp N, Andersen LB, Froberg K. Tracking of objectively measured physical activity from childhood to adolescence: the European youth heart study. Scand Med Sci Sport 2007; doi: 10.1111/j.1600-0838.2006.00622.x.

22 Fisher A, Reilly JJ, Montgomery C, Kelly L, Williamson A, Jackson DM, et al. Seasonality in physical activity and sedentary behavior in young children. Pediatr Exerc Sci 2005;17:31-40.

23 Office of Population and Census Surveys. Standard occupational classification. London: HMSO, 1991.

24 Riddoch C, Mattocks C, Deere K, Saunders J, Kirkby J, Tilling K, et al. Objective measurement of levels and patterns of physical activity. Arch Dis Child 2007;92:963-9.

25 Kirkwood BR, Sterne JAC. Essential medical statistics. 2nd ed. Oxford: Blackwell, 2003.

26 Treuth MS, Butte NF, Puyau M, Adolph A. Relations of parental obesity status to physical activity and fitness of prepubertal girls. Pediatr 2000;106:E49.

27 Kihlbom M, Johansson SE. Month of birth, socioeconomic background and development in Swedish men. J Biosoc Sci 2004;36:561-71.

28 Helsen WF, Hodges NJ, Van Winckel J, Starkes JL. The roles of talent, physical precocity and practice in the development of soccer expertise. J Sport Sci 2000;18:927-36.

29 Pfeiffer KA, Dowda M, Dishman RK, Mclver KL, Sirard JR, Ward DS, et al. Sport participation and physical activity in adolescent females across a four-year period. J Adolescent Health 2006;39:523-9.

30 Malina RM, Bouchard C, Bar-Or O. Growth, maturation and physical activity. Champaign, IL: Human Kinetics, 2004

31 Simonen RL, Perusse L, Rankinen T, Rice T, Rao DC, Bouchard C. Familial aggregation of physical activity levels in the Quebec family study. Med Sci Sport Exerc 2002;34:1137-42.

32 Gustafson SL, Rhodes RE. Parental correlates of physical activity in children and early adolescents. Sports Med 2006;36:79-97.

33 Ekelund U, Brage Sor, Froberg K, Harro M, Anderssen SA, Sardinha LB, et al. TV viewing and physical activity are independently associated with metabolic risk in children: the European youth heart study. PLoS Med 2006;3:e488.

34 Marshall SJ, Biddle SJ, Gorely T, Cameron N, Murdey I. Relationships between media use, body fatness and physical activity in children and youth: a meta-analysis. Int J Obes 2004;28:1238-46.

Accepted: 17 October 2007 